Wolfgang Huber

Manu L. N. G. Malbrain

\section{Goal-directed fluid resuscitation in acute pancreatitis: shedding light on the penumbra by dynamic markers of preload?}

Received: 27 November 2012

Accepted: 2 December 2012

Published online: 4 January 2013

(C) Springer-Verlag Berlin Heidelberg and ESICM 2012

This editorial refers to the article available at: doi: 10.1007/s00134-012-2775-x.

\section{W. Huber}

II. Medizinische Klinik und Poliklinik,

Klinikum rechts der Isar der Technischen Universität München, Ismaninger Straße 22, 81675 Munich, Germany

Tel.: +49-89-41405478

M. L. N. G. Malbrain (汭

Department of Intensive Care and High Care Burn Unit, Ziekenhuis Netwerk Antwerpen, ZNA Stuivenberg, Lange Beeldekensstraat 267, 2060 Antwerp 6, Belgium e-mail: manu.malbrain@skynet.be

\section{Introduction}

Acute pancreatitis (AP) is a potentially life-threatening disease with increasing incidence in Western countries. Severe AP (SAP) results in mortality of up to $42 \%$ [1-3]. Several recent studies have demonstrated improved early prediction of severity using a new scoring system (bedside index of severity in acute pancreatitis, BISAP) [4] or single parameters including elevated blood glucose [5], blood urea nitrogen (BUN) [4] and haematocrit $[6,7]$. Regarding therapeutic consequences, the association between elevated haematocrit and poor outcome is particularly of interest [6, 7]. These data suggest that impaired macro- and microcirculation with elevated BUN, decreased mean arterial pressure (MAP) and increased lactate [2] are crucial pathomechanisms for the development of SAP promoting pancreatic inflammation, particularly in parts of the pancreas with critical perfusion called the "penumbra" [3].

Consequently, early goal-directed volume resuscitation is an obvious strategy. Most guidelines recommend "liberal" fluid substitution in AP [1]. However, due to lack of evidence, clear-cut goals and tools to guide resuscitation have not been given. Frequently, fluid management is adjusted according to traditional pressure-based (barometric) markers of preload such as central venous pressure (CVP) and pulmonary capillary wedge pressure (PCWP). Particularly for the treatment of AP, this contradicts a substantial amount of evidence. Numerous studies have questioned the usefulness of CVP and PCWP for predicting volume responsiveness $[8,9]$ because there are several factors that affect these pressures such as ventilation forces, increases in intrathoracic pressure and intraabdominal pressure (IAP) induced by fluid extravasation (pleural effusion, ascites), and impaired gastrointestinal motility. Most of these factors are frequently found in AP, suggesting that CVP and PCWP are particularly inappropriate for fluid management in AP with increased IAP or intraabdominal hypertension (IAH) and risk of polycompartment syndrome $[10,11]$.

Nevertheless, there is a lack of data on better prediction of volume responsiveness and improved outcome using other haemodynamic monitoring tools in AP. This clearly emphasizes the merits of the study by Trepte et al. [12]. Although volumetric global end-diastolic volume index (GEDVI) and dynamic preload parameters such as stroke volume variation (SVV) and pulse pressure variation (PPV) have become widely available, this is one of the first studies evaluating these tools in AP. So far, only one study has demonstrated a superior association between (changes in) GEDVI and (changes in) cardiac index (CI) compared to CVP [13]. This study resulted in an ongoing multicentre randomized controlled trial (EAGLE) on early goal-directed therapy in AP using a 
complex algorithm based on GEDVI, extravascular lung water index and $\mathrm{pO}_{2} / \mathrm{FiO}_{2}$ [14].

In their experimental study in 34 pigs, Trepte et al. [12] compared a "traditional" algorithm aimed at CVP $>12 \mathrm{mmHg}$ and MAP $>60 \mathrm{mmHg}$ and an algorithm guided by left-ventricular SVV $(<10 \%)$, CI $(>2.51 / \mathrm{min} /$ $\mathrm{m}^{2}$ ), and MAP $(>60 \mathrm{mmHg})$. The CVP-based algorithm resulted in an excessive fluid load with 9,988 $\pm 2,240 \mathrm{ml}$ of crystalloids and 4,644 $\pm 1,117 \mathrm{ml}$ of colloids administered within $7 \mathrm{~h}$. This exceeded the resuscitation volumes in the SVV-guided group nearly threefold. CVPguided aggressive resuscitation resulted in significant decreases in survival, pancreatic oxygen tension and microcirculation compared to the SVV-guided group. Furthermore, extravascular lung water index-a parameter significantly associated with mortality-was significantly higher in the CVP-guided group.

\section{What is the impact of these findings on clinical routine?}

Overall this study further emphasizes the importance of goal-directed fluid management in AP as well as the need for appropriate endpoints. As in all controlled studies, differences in outcome might have been due to beneficial effects in the treatment group and/or due to detrimental effects in the controls. A retrospective study [15] demonstrates reduced mortality in case of early resuscitation compared to late resuscitation. However, excessive hydration with similar fluid volumes, as in the control group of Trepte et al., has been demonstrated to be detrimental in a clinical study [16]: aggressive hydration with $10-15 \mathrm{ml} / \mathrm{kg} \operatorname{min~h}$ (i.e. about $1 \mathrm{~L} / \mathrm{h}$ for a $70-\mathrm{kg}$ patient) on the day of admission resulted in increased mortality compared to controls with more moderate resuscitation with $5-10 \mathrm{ml} / \mathrm{kg} \operatorname{min~h}(30.6 \%$ vs. $10 \%)$. These findings were associated with a significantly higher incidence of abdominal compartment syndrome and sepsis in the high-volume resuscitation group. Nevertheless, general restriction of fluid resuscitation in AP would be the wrong interpretation since the less-hydrated groups with the more favourable outcome received early highvolume resuscitation markedly exceeding the recommendations of most guidelines [16, 17].

However, findings of Trepte et al. have to be analysed with caution because there are several potential differences between this animal study and the clinical setting. Treatment with different algorithms was started immediately after experimental induction of AP. In clinical routine, patients with AP present 12-36 h after the onset of pain [3]. Starting "re"-suscitation before established fluid loss might explain some of the findings of Trepte et al. In a clinical setting, patients with SAP frequently present with already established dramatic fluid shifts with intravascular hypovolemia, increased haematocrit and IAH. As a consequence of increased IAP, CVP is frequently elevated despite central hypovolemia, which might result rather in fluid restriction when using CVPbased algorithms. With normal mean values for CVP, MAP and CI without catecholamines, aggressive early hydration aimed at "supranormal" CVP might have resulted in detrimental over-hydration in the controls.

Despite some evidence for the usefulness of dynamic preload markers such as SVV and PPV, several shortcomings in the use of these markers particularly for early application in AP have to be kept in mind. The use of SVV indispensably requires controlled mechanical ventilation, which is not a realistic scenario in patients with SAP on admission. Furthermore, SVV/PPV are less useful in patients with IAH [18]. Increased IAP is common in SAP and one of the best outcome predictors [19]. Due to dependency of SVV and PPV on tidal volume [20], the ventilator setting used in the study (tidal volume $10 \mathrm{ml} /$ $\mathrm{kg}$, exceeding the current ARDS net recommendations) might have resulted in more liberal initial resuscitation.

\section{What are the implications for future research?}

This study is the first providing clear evidence for the use of volumetric and dynamic preload markers in SAP. In view of the complex and prolonged ICU courses in AP, strategies combining volumetric and dynamic parameters (when applicable) with functional tests (passive leg raising, end-expiratory occlusion) and also taking into account IAP and abdominal perfusion pressure may improve outcome of SAP.

Despite a certain complexity, these strategies will be necessary to address different requirements of fluid support during different stages of AP with an early "ebbphase" and a substantial risk in neglecting the appropriate turning point for initiating the "flow-phase" in patients with persisting capillary leakage and a high risk of fluid overload which is associated with a worse outcome [2023].

The data of Trepte et al. shed a little light on the penumbra of fluid management in (S)AP. Nevertheless, there is still "more to the picture than meets the eye...".

Acknowledgments W.H. is supported by a grant from the Deutsche Forschungsgemeinschaft (HU1707-2-1). WH and MLNGM are members of the medical advisory board of Pulsion Medical Systems (Munich, Germany), a monitoring company. 


\section{References}

1. Banks PA, Freeman ML; The Practice Parameters Committee of the American College of Gastroenterology (2006) Practice guidelines in acute pancreatitis. Am J Gastroenterol 101:2379-2400

2. Harrison DA, D'Amico G, Singer M (2007) The pancreatitis outcome prediction (POP) score: a new prognostic index for patients with severe acute pancreatitis. Crit Care Med 35:1703-1708

3. Phillip V, Huber W, Hagemes F, Lorenz S, Matheis U, Preinfalk S, Schuster T, Lippl F, Saugel B, Schmid RM (2011) Incidence of acute pancreatitis does not increase during Oktoberfest, but is higher than previously described in Germany. Clin Gastroenterol Hepatol 11:995-1000.e3

4. Wu BU, Johannes RS, Sun X, Tabak Y, Conwell DL, Banks PA (2008) The early prediction of mortality in acute pancreatitis: a large population-based study. Gut 57:1698-1703

5. Lankisch PG, Blum T, Bruns A, Dröge M, Brinkmann G, Struckmann K, Nauck M, Maisonneuve P, Lowenfels AB (2001) Has blood glucose level measured on admission to hospital in a patient with acute pancreatitis any prognostic value? Pancreatology 1:224-229

6. Brown A, Orav J, Banks PA (2000) Hemoconcentration is an early marker for organ failure and necrotizing pancreatitis. Pancreas 20:367-372

7. Lankisch PG, Mahlke R, Blum T, Bruns A, Bruns D, Maisonneuve P, Lowenfels AB (2001) Hemoconcentration: an early marker of severe and/or necrotizing pancreatitis? A critical appraisal. Am J Gastroenterol 96:2081-2085

8. Kumar A, Anel R, Bunnell E, Habet K, Zanotti S, Marshall S, Neumann A, Ali A, Cheang M, Kavinsky C, Parrillo JE (2004) Pulmonary arterial occlusion pressure and central venous pressure fail to predict ventricular filling volume, cardiac performance, or the response to volume infusion in normal subjects. Crit Care Med 32:691-699

9. Osman D, Ridel C, Ray P, Monnet X, Anguel N, Richard C, Teboul JL (2007) Cardiac filling pressures are not appropriate to predict haemodynamic response to volume challenge. Crit Care Med 35:64-68
10. Malbrain ML, Chiumello D, Pelosi P, Bihari D, Innes R, Ranieri VM, Del Turco M, Wilmer A, Brienza N, Malcangi V, Cohen J, Japiassu A, De Keulenaer BL, Daelemans R, Jacquet L, Laterre PF, Frank G, De Souza P, Cesana B, Gattinoni L (2005) Incidence and prognosis of intraabdominal hypertension in a mixed population of critically ill patients: a multiple-center epidemiological study. Crit Care Med 33:315-322

11. Malbrain ML, Wilmer A (2007) The polycompartment syndrome: towards an understanding of the interactions between different compartments! Intensive Care Med 33:1869-1872

12. Trepte CJC, Bachmann KA, Stork J, Friedheim T, Hinsch A, Goepfert MS, Mann O, Izbicki JR, Goetz AE, Reuter DA (2012) The impact of early goaldirected fluid management on survival in an experimental model of severe acute pancreatitis. Intensive Care Med. doi:10.1007/s00134-012-2775-x

13. Huber W, Umgelter A, Reindl W, Franzen M, Schmidt C, von Delius S, Geisler F, Eckel F, Fritsch R, Siveke J, Henschel B, Schmid RM (2008) Volume assessment in patients with necrotizing pancreatitis: a comparison of intrathoracic blood volume index, central venous pressure, and hematocrit, and their correlation to cardiac index and extravascular lung water index. Crit Care Med 36:2348-2354

14. US National Institutes of Health, ClinicalTrials.gov. http://www. clinicaltrials.gov/ct2/show/ NCT00894907?term=EAGLE + pancreatitis\&rank $=1$. Accessed $11 \mathrm{Dec}$ 2012

15. Gardner TB, Vege SS, Chari ST, Petersen BT, Topazian MD, Clain JE, Pearson RK, Levy MJ, Sarr MG (2009) Faster rate of initial fluid resuscitation in severe acute pancreatitis diminishes in-hospital mortality. Pancreatology 9:770-776

16. Mao EQ, Tang YQ, Fei J, Qin S, Wu J, Li L, Min D, Zhang SD (2009) Fluid therapy for severe acute pancreatitis in acute response stage. Chin Med J (Engl) 122:169-173
17. Malbrain ML, De laet I (2009) Functional hemodynamics and increased intra-abdominal pressure: same thresholds for different conditions? Crit Care Med 37:781-783

18. Gruenewald M, Renner J, Meybohm P, Höcker J, Scholz J, Bein B (2008) Reliability of continuous cardiac output measurement during intra-abdominal hypertension relies on repeated calibrations: an experimental animal study. Crit Care 12(5):R132

19. Rosas JM, Soto SN, Aracil JS, Cladera PR, Borlan RH, Sanchez AV, Ros FB, Posa LG (2007) Intra-abdominal pressure as a marker of severity in acute pancreatitis. Surgery 141(2):173-178

20. da Silva Ramos FJ, de Oliveira EM, Park M, Schettino GP, Azevedo LC (2011) Heart-lung interactions with different ventilatory settings during acute lung injury and hypovolaemia: an experimental study. Br J Anaesth 106(3):394-402

21. Cordemans C, De laet I, Van Regenmortel N, Schoonheydt K, Dits H, Martin G, Huber W, Malbrain ML (2012) Aiming for a negative fluid balance in patients with acute lung injury and increased intra-abdominal pressure: a pilot study looking at the effects of PAL-treatment. Ann Intensive Care 2(Suppl 1):S15

22. Malbrain ML, Cheatham ML, Kirkpatrick A, Sugrue M, Parr M, De Waele J, Balogh Z, Leppäniemi A, Olvera C, Ivatury R, D'Amours S, Wendon J, Hillman K, Johansson K, Kolkman K, Wilmer A (2006) Results from the international conference of experts on intra-abdominal hypertension and abdominal compartment syndrome. I. Definitions. Intensive Care Med 32(11):1722-1732

23. Wiedemann HP, Wheeler AP, Bernard GR, Thompson BT, Hayden D, deBoisblanc B, Connors AF Jr, Hite RD, Harabin AL (2006) Comparison of two fluid-management strategies in acute lung injury. N Engl J Med 354(24):2564-2575 